\title{
Therapeutic Strategies (Resiliency \& Self-Control) in Reducing Late Adolescents' Risky Smoking Behaviour in Oyo State, Nigeria
}

\author{
Titilola Adedoyin Adebowale ${ }^{1}$ \\ ${ }^{1}$ Department of Social Work, University of Ibadan, Ibadan, Nigeria \\ Correspondence: Titilola Adedoyin Adebowale, Department of Social Work, University of Ibadan, Ibadan, \\ Nigeria. Tel: 234-080-5530-7417. E-mail: titade07@yahoo.com
}

Received: February 28, 2013

Accepted: April 1, $2013 \quad$ Online Published: May 21, 2013

doi:10.5539/ijps.v5n2p85

URL: http://dx.doi.org/10.5539/ijps.v5n2p85

\begin{abstract}
Cigarette Smoking is one of the risky behavioural problems of exploration and experimentation of the adolescents. One of every six Nigerian adolescents is a smoker, hence the adolescents need help. This study investigates the efficacy of resiliency and self-control strategies on the management of late adolescents' risky smoking behavior. The study adopted experimental design with a 3x2 factorial index. 120 senior secondary school students were randomly selected from three secondary schools, consisting of only male students with diverse characteristics. The treatment lasted for eight weeks. Adolescents Smoking Behaviour Assessment Questionnaire was used for the study. Statistical Package for Social Sciences (SPSS) was adopted for the reliability with internal consistency of $0.95(\mathrm{r}=0.95)$. The choice of items and its selection determined the content validity, with 25 items finally used. Two hypotheses were postulated and tested at 0.05 level of significance. The findings reveal that self-control strategy significantly affect smoking behaviour of the late adolescents $\left(\mathrm{F}_{11}\right.$, ${ }_{39)}=18.103, \mathrm{P}<0.05$ ). Also resiliency strategy significantly affect the smoking behavior of the late adolescents $\left(\mathrm{F}_{(1,39)}=15.883, \mathrm{P}<0.05\right)$. The two strategies are effective in the management of late adolescents' risky smoking behaviour. The duo can always complement each other in treatment.
\end{abstract}

Keywords: therapeutic strategies (resiliency \& self-control), late adolescents, smoking behaviour

\section{Introduction}

Adolescence is the phase of life between ages 0-19 years (WHO, 1993). It is believed that more than one fourth of the world population of 6 billion is between the ages of 10 and 24 and this is the largest group ever to enter adulthood (Boroffice, 2004). This period is marked by significant changes. Physically, the adolescent experiences puberty that brings about development of secondary characteristics and the attendant emotional and intellectual changes. Experimentation and exploration are believed to be the hallmark of adolescence. The adolescent tends to develop a feeling of autonomy of independence from adult control, as he/she acquires some of the skills necessary for functioning in the adult world. Buckingham (1990) described the stage as a time of growing, trying new things, studying and learning. It is well known that rebellion or as a sigh of maturity but it ends up being addictive behaviour (Vardavas, 2010).

According to world health organization (WHO, 2011), smoking is the leading preventable cause of disease and premature death in the world. Yet the world consumption of cigarettes is estimated at around six hundred billion cigarettes per year. The total number s to the grave annually; this includes both passive and active smokers. Smoking is becoming one of the important mortality risk factors not only in industrialised countries but also in developing countries. Many smokers begin during adolescence or early adulthood (The World Health Organisation \& the Institute for Global Tobacco Control, John Hopkins School of Public Health 2001). Flore, Jean Baker (2008) also asserted that Tobacco addiction usually begins in childhood or adolescence. Numerous reports have documented the health status of youths in Nigeria, America and other industrialized as well as least developed countries. Young people are highly vulnerable to the profound changes in the social environment that have occurred recently and which have considerable effects on their health. The National Longitudinal Study of Adolescent Health (Minnesota Adolescent Health Action Plan, 2002), American school based study of the health related behaviour of adolescents, designed to measure; the social settings of adolescents' lives in which adolescent connect to their social world, and the influence of these social settings, seem to corroborate the assertions of Moronkola and Aremu (2004) that unknown to the adolescents, most of the contending challenges 
force them into taking risks which usually have future health implications. In view of this, threats to the adolescents' health stem primarily from their risky behavior. The use of tobacco poor nutrition and sedentary life styles can lead to health problems in later years (Hawkin, Catalano \& Miller, 1992).

Cigarettes, the most popular method of smoking consist of finely shredded tobacco rolled in lightweight paper. Scientists have made tremendous success in establishing the much needed fact that cigarette smoke contains various toxic substances that trigger off or exhilarate the tobacco related diseases. The chemical substances in cigarette smoke which are of medical importance can be summarized as cancer producing substances, irritants, nicotine, carbon-monoxide and other chemically active gases including oxides of nitrogen and hydrogen cyanide. Each year tobacco claims the lives of some 2-5 million people, this figure is estimated to reach 8 million by the year 2025 (Mackay, 1990). Smoking has been found to have an effect on the smokers as mentioned in population reports published by Population Information Programme of the John Hopkins University, U.S.A. It shows that the use of tobacco is one of the foremost public health problems in the world. The death rates of men who smoke cigarette were about ten times higher for lung cancer, five times higher for bronchitis, emphysemas and asthma, and two to three times higher for heart disease. The result also revealed that tobacco related diseases, subtracted five to ten years from the life of an average smoker. For all smokers the risk of death increased progressively with the amount of cigarettes smoked.

World Bank (2004) reports on Tobacco control and the attainment of the Millenium Development Goals reported that one of every six students in Nigeria admitted to smoking cigarettes. Mr. Eze Eluche, the Executive Director of the people against Drug Dependence and Ignorance, says smoking among students in Nigeria may even be more common than studies reveal, that the influx of tobacco multinationals hold great danger for the future. And that we should concern ourselves with what may happen in the future because tobacco companies are targeting youths and making it look as if it is cool to smoke (Punch, June 13, 2006).

Some research has been carried out on the effects and implications of cigarette smoking on the smokers and the society. Nichiter and Cartwright (1991) reviewed the data on tobacco cultivation and its impact on ecology, global smoking trends, the economy of the tobacco industry, cigarette marketing, and projected levels of morbidity. They focused on the effects of smoking, not just on the consumer but also on the household. Adelman, Duggan, Hauptman. Joffe (2001) revealed in their study that a school based curriculum for adolescent smoking cessation is more effective than an informational pamphlet and reduces cigarette use by adolescents. Redmond (2002) in this study, smoking reduction among high school seniors, found that the most effective variables involve. Smoking related beliefs and perfection, particularly in anticipated future smoking status, attempted quitting number of smoking friends, and perceptions of other smokers. Cigarette smokers have a higher risk of developing a number of chronic disorders. Consequences of smoking include fatty build ups in arteries, several types of cancer and chronic obstructive pulmonary disease (U.S. Public Health Services, 1997). Igwe (1992) opened in his finding that improved family and community support would prevent many youths in Nigeria from risk behaviour including smoking, drinking alcohol and illicit drugs.

In order to curb this nefarious activity of the adolescents in their smoking behaviour, resiliency and self-control strategies have been identified suitable. For the past three decades, resilience research has grown in popularity and various models and data have emerged as well as criticism about the usefulness of this construct in psychology (Masten, 2001). Resilience simply refers to the development of competence in the face of adversity. Several studies have uncovered a core set of factors that have consistently been shown to promote competence despite adversity. There are other integrations involving these several levels that are involved in the design and delivery of successful prevention programmes for at-risk youth. These factors include relationships with caring pro-social adults, good problem-solving skills, and good intellectual functioning (Masten \& Coatsworth, 1998). Risk and protective factors are not just opposite side of the same coin, protective factors exert their benefits only when a risk is present (Rutter, 1987). All the necessary ingredients for resiliency are embedded in the stakeholders such as the individual adolescent, family, peer, work-setting and community.

Self-control strategy is another intervention that is suitable in reducing the smoking behaviour of the late adolescents. One treatment may not be adequate for treating the problem of the adolescents because their problems have diverse causes (Dishion, Andrew, Kavangh, Sobermand, 1996), hence it calls for more treatments for reasonable cure. It is clear to a greater extent that self-control techniques are subject to conflicting reinforcement. In most cases, immediate punishment, discomfort is followed later by reward (Kanfer, 1975). It is under this special reinforcement condition that Kanfer (1972) maintain that a person may exhibit self-control by performing the responses that will avoid future punishment at the expense of present reward thereby refraining from the tempting response that could bring immediate gratification. This indicates that when an adolescent smoker remembers the future danger in smoking, he will voluntarily withdraw from indulging in it, without 
anybody forcing him to do so. Having identified self-control as being an appropriate strategy for the management of smoking behaviour, the adolescents need orientation in the skills involved and with their understanding, the skills will increase.

The backbone of this strategy is for the adolescents not to think of themselves as having no will power to cope, they need to think positively to eliminate inner weakness. Self-control, according to Kanfer and Karoly (1972) and Kanfer (1972) is viewed as the final outcome of a three stage self-regulating process involving monitoring, self-evaluation and self-reinforcement which any serious minded person should be able to cope with because it does not require force but skills to go through it successfully. In principle, almost any behavioural problem can be tackled by the application of self-control procedures, provided that the client has the intelligence sufficient to comprehend to carry out such a programme.

\subsection{Statement of the Problem}

The adolescents are full of life and strength that they usually channel to injurious adventures that can endanger their lives both now and in future. Obioha (2004) in his study concluded that adolescents irrespective of their individual characteristics are vulnerable to cigarette smoking. He later suggested that the government should make appropriate policies prohibiting the sale of cigarette to adolescents and youths generally. This suggestion was supported by ASDA, a leading supermarket in U.K. the above suggestion may not be adequate, because the fundamental human rights may be negated. The late adolescents in their matured age need to participate fully in the eradication of this health hampering habits hence the researcher is employing the two strategies, self-control and resiliency, to reduce their smoking habits.

\subsection{Research Hypotheses}

The following hypotheses were formulated, and tested at 0.05 level of significance:

1) There is no statistically significant difference in the management of smoking behaviour scores between the late adolescents exposed to self-control and the control group.

2) There is no statistically significant difference in the management of smoking behavior scores between the late adolescents exposed to resiliency and the control group.

\section{Methodology}

\subsection{Research Design}

The study adopted a pre-test, post-test, experimental design with a $3 \times 2$ factorial design in which there were three rows consisting of the two treatment strategies, resiliency group, self-control group and the control group (non-treatment groups); and the two columns for the early and late adolescents.

\subsubsection{Sample}

Adolescents from three secondary schools in Oyo State were subjects for the study. The participants were randomly selected from three schools in Ibadan North Local Government. The researcher worked with selected representation of the population of the entire adolescents (samples). A total of one hundred and twenty (120) participants which were made up of only males from SS II were used, with their ages ranging from 10-14 (early adolescent) and 15-19 (late adolescent).

\subsection{Instrumentation}

Two instruments were used in this study. The first instrument, Smoking Behaviour Scale (SBS) was used in screening the SS II students to identify smoking behaviour among the students. After screening, 120 were selected depending on their response to the SBS. The SBS was initially administered to 30 students to know if it would clearly give out students who were prone to smoking cigarette, with the internal consistency coefficient $0.85(\mathrm{r}=0.85)$. The second instrument, Adolescents Smoking Behaviour Assessment Questionnaire (ASBAQ) developed by the researcher, was also used for data collection. The questionnaire had two sections. Section A explored the demographic information of the participants. Section B contains twenty-five items on Adolescents' Smoking Behaviours. The initial 33 items on ASBAQ were administered to a sample of 45 adolescents in three secondary schools within Ibadan. The section is drawn in a Likert-type format and the items explored smoking behavior habit. The items were subjected to computerized item analysis, using Statistical Package for Social Science (SPSS) and items that recorded low reliability were eliminated remaining 25 items with internal consistency coefficient of $0.95(\mathrm{r}=0.95)$. The content validity was determined by the choice of items and subsequent item selection procedure ensured that the items actually described Adolescents' Smoking Behaviours among youth. 


\subsection{Procedure}

Preliminary visits were made to the three schools randomly chosen in Ibadan North Local Government Area of Oyo State to reflect the urban nature of the schools within the local government. The main purpose of the visits was to get the researcher acquainted with the schools and to address the students educating them about the importance of the research focus to them, the schools and the society at large. With the information at hand the review of literature, possible treatment goals were then set for this study.

1) Three schools from Ibadan North Local Government were randomly chosen. Although, the schools are in the same local government area but they are far from each other on different axis to avoid possible contamination.

2) All the arms of SS II in each of the three schools were screened using, the SBS rating scale developed by the researcher. 180 subjects were randomly chosen here and systematically reduced to the required number 120 for the research. The participants were randomly allocated into the two experimental groups and the control group.

3) All the treatment groups and the control groups were taught and tested respectively within the school environment but during break time and after school hours. The experiment was completed within a school term to avoid time lag effects on the study.

4) All participants group in this study were given a pre-test using the measuring instruments designed for the study. The treatment strategies on Resiliency Training and self-control skills were used on groups I and II respectively. After the treatment, the same instrument was used for all the groups to determine the post-treatment scores.

\section{Data Analysis}

The Analysis of Co-variance (ANCOVA) was the main statistical procedure utilized by the analysis of available data testing the hypotheses.

\section{Results}

The first hypothesis states that there is no significant difference in the management of smoking behaviour scores between early adolescents exposed to self-control strategy and the control group.

Table 1. Effects of self-control and control on smoking behaviour of late adolescents

\begin{tabular}{ccccccc}
\hline Age & Source & Sum of Squares & df & Mean Square & F & P \\
\hline 15-19 years & Corrected Model & 6420.907 & 2 & 3210.454 & 75.47 & .000 \\
& Intercept & 46.430 & 1 & 46.430 & 1.09 & .303 \\
& Pretest & 5063.682 & 1 & 5063.682 & 119.04 & .000 \\
& Treatment & 770.037 & 1 & 770.037 & 18.10 & .000 \\
& Error & 1573.868 & 37 & 42.573 & & \\
& Total & 50701.000 & 40 & & & \\
\hline
\end{tabular}

0.05 Level of significant

Results on Table 1 show that self-control significantly affect smoking behaviour of the late adolescents, the hypothesis is rejected $\left(\mathrm{F}_{(1,39)}=18.103, \mathrm{P}<0.05\right)$. This means that self-control strategy has positive effect on the late adolescents exposed to the treatment.

The second hypothesis states that there is no significant difference in the management of smoking behaviour scores between the late adolescents exposed to resiliency and the control group. 
Table 2. Effect of resiliency and control on the behaviour of the late adolescents

\begin{tabular}{lllllll}
\hline Age & Source & Sum of Squares & Df & Mean Square & F & P \\
\hline $15-19$ years & Corrected Model & 4403.798 & 2 & 2201.899 & 21.88 & .000 \\
& Intercept & 757.698 & 1 & 757.698 & 7.329 & .010 \\
& Pretest & 3472.573 & 1 & 3472.573 & 33.574 & .000 \\
& Treatment & 1642.758 & 1 & 1642.758 & 15.883 & .000 \\
& Error & 3826.977 & 37 & 103.432 & & \\
& Total & 535191.000 & 40 & & & \\
\hline
\end{tabular}

0.05 Level of significance

Results on table 2 show that resiliency significantly affect smoking behavior in the late adolescents, therefore the hypothesis was rejected $\left(\mathrm{F}_{(1,39)}=15.883, \mathrm{P}<0.05\right)$. This also connotes that resiliency as a strategy helps to reduce the smoking behavior of the late adolescents.

\section{Discussion}

The findings show clearly that self-control is effective among the late adolescents due to the training they received. This supports the assertion of Dacey and Kenny (1997), that during adolescence, the ability of young people to perceive, comprehend and retain information seems to improve with age and instructions. Thus older adolescents tend to have a greater ability than younger adolescents for dealing with complex social and ethical issues because they have a more complex level of information processing. This reflected in the treated group unlike the control group that did not have the opportunity to exercise such skills under this study because they were not opened to such information. There was also a wide gap between resiliency strategy group scores and that of the control. This shows that resiliency on late adolescents here is effective. This findings negates the criticism of resilience studies by some researchers, who argued that the considerable variation in defining key constructs has undermined the interpretability of the subsequent results; others have contended that some variations in methodology is essential in expanding our knowledge of this construct (Masten, 2001). Despite these inconsistencies in the past researches on resiliency, several studies and researches (Rutter, 1987) including this research work have uncovered a set of factors that have consistently been shown to promote competence despite adversity. The late adolescents in the treated group got the knowledge of the sense of connectedness to their parents and families, their feelings of closeness to their parents, satisfaction with family relationships and their sense of being loved and cared for.

\subsection{Implications of the Findings for Social Welfare Counselling Practice}

The lives of the adolescents may be more endangered with risky smoking behavior, if caution is thrown into the winds, because smoking is being targeted towards the adolescents, due to their nature and character (Arnett, 2001). For adulthood to be salvaged from the smoking problem, the stage (adolescence) before it has to be considered. Many researches and studies have tried to put the problem of smoking among adolescents under control, but some of the suggestions have not really helped the situation, because the adolescents themselves are not directly involved in the solution process, as supported by Adelman et al (2001). According to them the adolescents' smoking behavior can be reduced through the curriculum instead of the use of pamphlet and campaigning against smoking. This is also the view and stand of the researcher. Both resiliency and self-control strategies could be inculcated in the curriculum just as self-defence is introduced into the educational system of some developed countries such as Japan, China, Great Britain etc. The two strategies would involve the adolescents and the educational stakeholders, such as, family, school, peer, community, workplace and even the government in the implementation.

Smoking behavior of the adolescents would be among several behavioural problems to be curbed. Other areas where adolescents risk their lives will be eradicated, such as violence, reckless driving, robbery, sexual abuse, suicide, teenage pregnancy e.t.c. It is also essential to say that the adolescents who have problem of withdrawal from smoking cigarette can be referred, assisted and treated by a more knowledgeable guidance counsellor for the cessation of smoking behavoiur. And any female found in the same problem could as well be helped with the study.

In conclusion, self-control has been long and widely used to solve all behavioural problems people encounter. Even though resiliency is a bit new in the field of psychology but it could be encouraged as part of growth and development because much cannot be acquired through it within a very short period of time. Hence, resiliency is 
found to be a good behavior modifying technique that could also join those that are already in use. However, the two strategies, self-control and resiliency can always complement each other in the management of adolescent's risky smoking behavior.

\section{References}

Adelman, W. P., Duggan, A. K., Hanptman, P., \& Joffe, A. (2001). Effectiveness of a High School Smoking Cessation Programme Pediatrics. Journal of Pediatrics, 107(4).

Arnet, J. (2001). Adolescents responses to cigarette advertisements for Five "YouthBrands" and one "Adult Brand". Journal of Research on Adolescence, 11, 425-443. http://dx.doi.org/10.1111/1532-7795.00019

Boroffice, O. B. (2004). Recreation and Health Behaviour of Adolescents. In I. A. Nwazukwe, Y. Bamgbose, \& O. A. Moronkola (Eds.), Contemporary issues and Researches on Adolescents. Ibadan: Royal people publishers.

Buckingham, J. (1990). Coming Alive. New Jersey: Plainfield.

Dishion, T. J., Andew, D. W., Kavangh, K., \& Sobermand, L. H. (1996). Preventive Interventions for high-risk youth: The adolescent transition programme. In R. D. Peters, \& R. J. McMahon (Eds.), Preventing Childhood disorders Substance abuse, and delinquency (pp. 184-214). Thousand Oaks, C.A: Sage.

Fiore, M-Jaen, C., \& Baker, T. (2008). Treating Tobacco Use and Dependence: Update-Clinical Practice Guideline. Rockville, MD: US Department of Health and Human Services: Public Health Service.

Hawkins, J. D., Catalano, R. D., \& Miller, J. Y. (1992). Risk and Protective Factors for Alcohol and other Drugs, In Adolescence and Early Adulthood: Implications for substances abuse prevention. Psychological Bulletin, 112(1), 64-100. http://dx.doi.org/10.1037/0033-2909.112.1.64

Igwe, S. A. (1992). Nigerians Youth at Risk. Afr. Health, 14(4), 45-46.

Kanfer, F. H., \& Karoly, P. (1972). Self-control: A behavioural Excursion into the lion's den. Behavior therapy, 3, 388-416. http://dx.doi.org/10.1016/S0005-7894(72)80140-0

Kanfer, F. H. (1972). The maintenance of behavior by self-generated stimuli and reinforcement. In A. Jacob, \& L. B. sachs (Eds.), The Psychology of private events (pp. 39 -57). New York: Academic Press.

Kanfer, F. H. (1975). Self-Management techniques. In F. H. Kanfer, \& A. P. Goldstein (Eds.), Helping people change. New York: Pergaon.

Machay, J. A. (1990). Peter And Parental Influence on Adolescent Substance Use: Path Analysis. The International Journal of Addiction, 29(50), 647-996.

Masten, A. S. (2001). Ordinary magic- Resiliency Processes in Development. American Psychologist, 56(3), 227-238. http://dx.doi.org/10.1037/0003-066X.56.3.227

Masten, A. S., \& Coatsworth, J. D. (1998). The development of competence in favourable and Unfavourable environment: lessons from successful children. American Psychologist, 53, 205-220. http://dx.doi.org/10.1037/0003-066X.53.2.205

Minnesota Adolescent Health Action Plan. (2002). Being, belonging, becoming. Minnesota Department of Health.

Moronkola, O. A., \& Aremu, A. O. (2004). The challenges of Adolescents in Nigeria: Health Education, Promotion and counseling Implications. In I. A. Nwazuoke, Y. Bamgbose, \& O. A. Moronkola (Eds.), Contemporary Issues and Researches on Adolescents. Ibadan: Royal People Publishers.

Nichiter, M., \& Cartwright, E. (1991). Saving the children of the Tobacco Industry, Medical Anthropology, Quarterly. Contemporary issues of Anthropology in International Health, 5(3), 236-256.

Obioha, E. E. (2004). The Attitude and Reception of High School Studies in Onitsha Metropolis towards Cigarette Smoking. In I. A. Nwazuoke, Y. Bamgbose, \& O. A. Moronkola (Eds.), Contemporary issues and Research on Adolescent. Ibadan, Royal People Publishers.

Redmond, W. H. (2002). Smoking Reduction Among High School Seniors: A test of selected indicators. Journal of Adolescent Health, 31(5), 417-424. http://dx.doi.org/10.1016/S1054-139X(02)00406-8

Rutter, M. (1987). Psychosocial resilience and protective mechanisms. American Journal of Orthopsychiatry, 57, 316-331. http://dx.doi.org/10.1111/j.1939-0025.1987.tb03541.x

U.S. Public Health Services. (1997). The Health Consequence of smoking. USGPO. 
Vardanvas, C. (2010). Key Points in Preventing Tobacco Use among Adolescents. Tobacco induced Diseases $8: 1$.

WHO. (1993). The Health of Young People. A Challenge \& A promise. Geneva.

World Bank. (2004). Adolescent health and Development in Africa: World Bank brings together policy maker and youth for dialogue on their future Development News Media Center.

World Health Organization. (2011). WHO report on the global Tobacco epidemics, warning about the dangers of Tobacco. Retrieved from http//:www.who:int/tobacco/globalreport /2011/ html 